\title{
ANÁLISE BIBLIOMÉTRICA DAS TENDÊNCIAS DO USO DO ÍNDICE DRASTIC
}

\author{
Francisco Afonso Cavalcanti-Júnior $^{(a)}$, Déborah Oliveira ${ }^{(b)}$ \\ (a) Departamento de Geografia/Faculdade Filosofia, Letras e Ciências Humanas/ Universidade de São Paulo, \\ cavalcantijunior@usp.br \\ (b) Departamento de Geografia/Faculdade Filosofia, Letras e Ciências Humanas/ Universidade de São Paulo, \\ debolive@usp.br
}

\section{Eixo: Geografia Física e desastres naturais}

\begin{abstract}
Resumo
As águas subterrâneas são recursos naturais importantes para o abastecimento humano, principalmente em regiões onde há escassez de água superficial. Muitos trabalhos, e vários métodos, vêm sendo desenvolvidos para estudar o seu grau de contaminação ou exposição. O Índice DRASTIC é atualmente um dos principais que estuda a sua vulnerabilidade a essa condição, porém em uma breve busca no site Web of Science não foram encontrados trabalhos bibliométricos que analisassem as tendências do seu uso e nem do termo "vulnerabilidade" presente na maioria dos trabalhos. Desta forma, buscou-se realizar uma análise dessas tendências por meio da análise bibliométrica. Os resultados, até o momento, indicam uma tendência do Índice DRASTIC em consolidar o conceito de vulnerabilidade entre os pesquisadores da área como a condição ou estado das águas subterrâneas a ser estudada, apontando ainda um crescimento de produção na temática, sobretudo, em países emergentes e em desenvolvimento.
\end{abstract}

Palavras-chave: Águas subterrâneas, Vulnerabilidade, Contaminação.

\section{Introdução}

O ciclo hidrológico cumpre papel importante na existência e manutenção do ecossistema terrestre e é o responsável pela distribuição de água doce no planeta, dessa forma, de toda precipitação, parte evapora, parte escoa para os rios e mares e uma outra parte infiltra alimentando aquíferos e lençóis freáticos que constituem as águas subterrâneas.

Por sua alta qualidade, resultado da filtragem por sucessivos processos físico-químicos e biológicos, e por sua abundância as águas subterrâneas se configuram como um valioso recurso para abastecimento humano, principalmente em regiões onde as águas superficiais são mais escassas e desta forma demandando uma atenção especial à sua forma de exploração, monitoramento e preservação.

As principais ameaças à qualidade dessas águas dizem respeito aos prováveis contaminantes biológicos e químicos nelas presentes e que podem causar danos à saúde humana quando consumidas. Porém, se faz importante destacar que essas substâncias já ocorrem naturalmente na litosfera e que em muitos casos 
poderão causar efeitos adversos na saúde humana dependendo dos seus graus de concentração (SELINUS, 2006). As rochas são as principais fontes de minerais na superfície terrestre e os disponibilizam para os sedimentos e solos, mas determinadas regiões podem concentrar maiores teores reverberando na subsuperfície.

No mundo globalizado e de intensa urbanização os processos antrópicos têm ocupado papel de destaque nos riscos de contaminação dos solos e, consequentemente, no grau de vulnerabilidade das águas subterrâneas a eles.

Em virtude da importância desse recurso natural, já mencionado anteriormente, nas últimas décadas vem crescendo o interesse pelos estudos na temática, bem como as diversas metodologias de investigação, em especial o Índice DRASTIC.

Em uma breve busca no banco de dados dos sites Web of Science e Science Direct foram encontrados, respectivamente 342 e 1.713 trabalhos relacionados às palavras-chave DRASTIC, Groundwater e Vulnerability, resultados superiores se comparados com buscas substituindo a primeira palavra-chave por outros métodos na mesma temática, como o GOD (Groundwater occurrence, Overall lithology of the unsaturated zone, Depth to the water table), por exemplo.

Apesar de obter vantagem no número de publicações não foram encontrados trabalhos bibliométricos que avaliassem a difusão do uso do Índice DRASTIC ou mesmo sua preferência, visto que ele demanda o levantamento de um número de atributos superiores aos dos outros métodos e por vezes tornando os estudos mais complexos.

Sendo assim, buscou-se realizar um levantamento bibliométrico sobre trabalhos com uso do Índice DRASTIC voltados para os estudos da vulnerabilidade à contaminação das águas subterrâneas, visando analisar suas tendências a nível global.

\section{2. Índice DRASTIC}

O Índice DRASTIC começou a ser difundido por uma equipe de estadunidenses liderados por Linda Aller, consiste em uma metodologia que permite avaliar a poluição de áreas e o potencial da vulnerabilidade intrínseca à contaminação das águas subterrâneas (ALLER et al., 1987), esse método é aplicado a partir de sete parâmetros (Figura 1) cujas suas iniciais, em inglês, formam o acrônimo DRASTIC. D Profundidade do topo do aquífero (Depth to the water table), $\mathbf{R}$ - Recarga do aquífero (net Recharge), $\mathbf{A}$ Material do Aquífero (Aquifer material), S - Tipo de Solo (Soil type), T - Topografia (Topography), I Impacto da Área Não-Saturada ou Vadosa (Impact of the vadose zone) e C - Condutividade hidráulica do aquífero (Conductivity), o índice é calculado pela seguinte equação: 


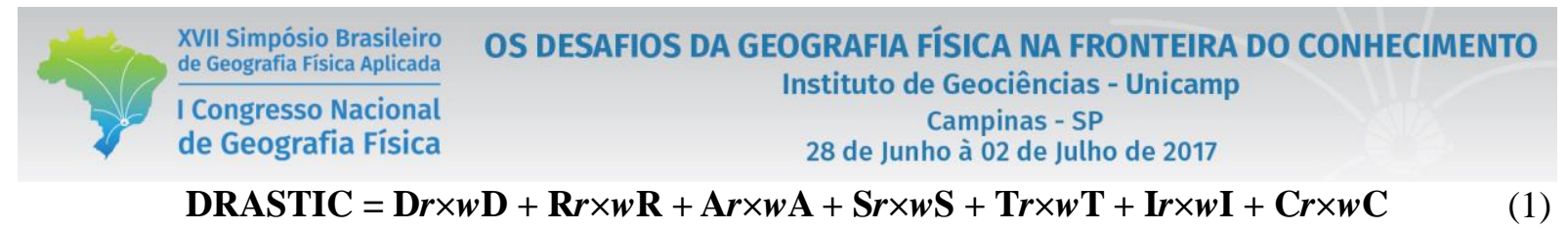

Cada parâmetro é representado por um elemento hidrogeológico com a letra $r$, aos quais são atribuídos valores variando de 1 a 10, o $r$ é multiplicado pelo valor de $w$ que corresponde ao peso atribuído em função de sua importância e que varia de 1 a 5 (ALLER et al., 1987; CARVALHO, 2013; GUIGUER; KOHNKE, 2002) (Tabela 1).

Tabela I - Atribuição de pesos para a importância dos parâmetros.

\begin{tabular}{|c|c|}
\hline Parâmetro & Peso \\
\hline D & 5 \\
\hline R & 4 \\
\hline A & 3 \\
\hline S & 2 \\
\hline T & 1 \\
\hline I & 5 \\
\hline C & 3 \\
\hline
\end{tabular}

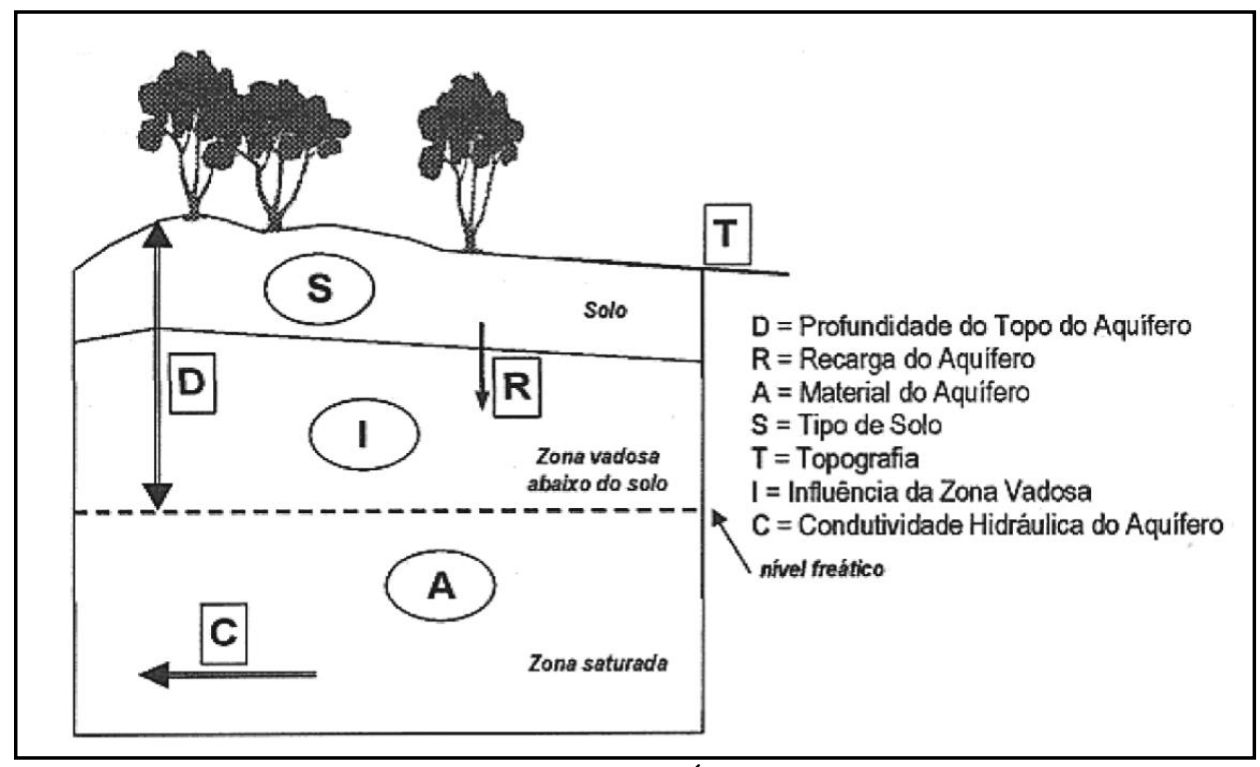

Figura 1 - Parâmetros do Índice DRASTIC.

Fonte - (OLIVEIRA; LOBO FERREIRA, 2002).

\section{Vulnerabilidade das águas subterrâneas}

O conceito de vulnerabilidade das águas subterrâneas baseia-se nas suposições de que um ambiente físico (geológico e pedológico) pode proporcionar certo grau de proteção às águas subterrâneas em relação aos impactos naturais e humanos e que alguns aquíferos são mais vulneráveis a esses impactos do que outros (RICHTS; VRBA, 2016; VRBA; ZAPOROŽEC, 1994), portanto, dependerá das características do aquífero (litologias, porosidade e outros), da área (uso do solo, topografia e outros) e do contaminante 
(mobilidade, densidade e outros) (GUIGUER; KOHNKE, 2002). Nesse sentido, a vulnerabilidade das águas subterrâneas torna-se uma condição intrínseca ao sistema natural e que, portanto, depende da sensibilidade aos impactos dos processos naturais e/ou humanos e a capacidade desse sistema de reagir a eles (VRBA; ZAPOROŽEC, 1994).

\section{Bibliometria}

A análise bibliométrica tem se apresentado no meio científico e acadêmico como uma ferramenta que busca investigar a relação entre as citações, volume e periodicidade das publicações e as revistas difusoras de conhecimento.

O seu precursor foi Alan Pritchard, que muito contribuiu para o desenvolvimento do método com o trabalho "Statistical bibliography or bibliometrics", sendo este o mais citado dos seus trabalhos e um dos mais citados na área. Ele definiu a bibliometria como a aplicação dos métodos estatísticos e matemáticos às produções bibliográficas e outros meios de comunicação (PRITCHARD, 1969).

O desenvolvimento da tecnologia, em especial dos computadores e o surgimento da Internet, foi fundamental para representar graficamente as relações estabelecidas a partir da análise bibliométrica, produzindo assim mapas neurais.

A partir do referido desenvolvimento surge o mapeamento bibliométrico, este consiste no processo que sistematizar a análise da produção literária das pesquisas para gerar um produto visual da estrutura organizacional das publicações (GAO et al., 2016), ou seja, para criar e visualizar mapas bibliométricos (VAN ECK et al., 2010). Dentre as principais técnicas desse tipo de visualização destaca-se o VOS Viewer, um aplicativo computacional desenvolvido por um grupo de pesquisadores da Leiden University, na Holanda.

\section{Metodologia}

Foram estabelecidas 3 palavras-chave que nortearam a pesquisa no banco de dados, elas foram:

- DRASTIC (referente ao método de estudo);

- Groundwater (água subterrânea - objeto estudado);

- Vulnerability (vulnerabilidade - condição estudada).

As palavras-chave foram usadas em inglês, devido a 99,41\% dos artigos na área terem sido publicados nesse idioma. As buscas foram realizadas em algumas plataformas como os sites Science Direct e Web of Science, porém somente nesse último foi possível exportam os dados e analisá-los no aplicativo VOS Viewer. A busca com essas palavras-chave retornou com 342 documentos publicados até 10/03/2017. O 
procedimento metodológico consistiu em 3 grandes etapas; definição do tema, pesquisa no bando de dados e análise bibliométrica, que se desdobraram em outras etapas (Figura 2).

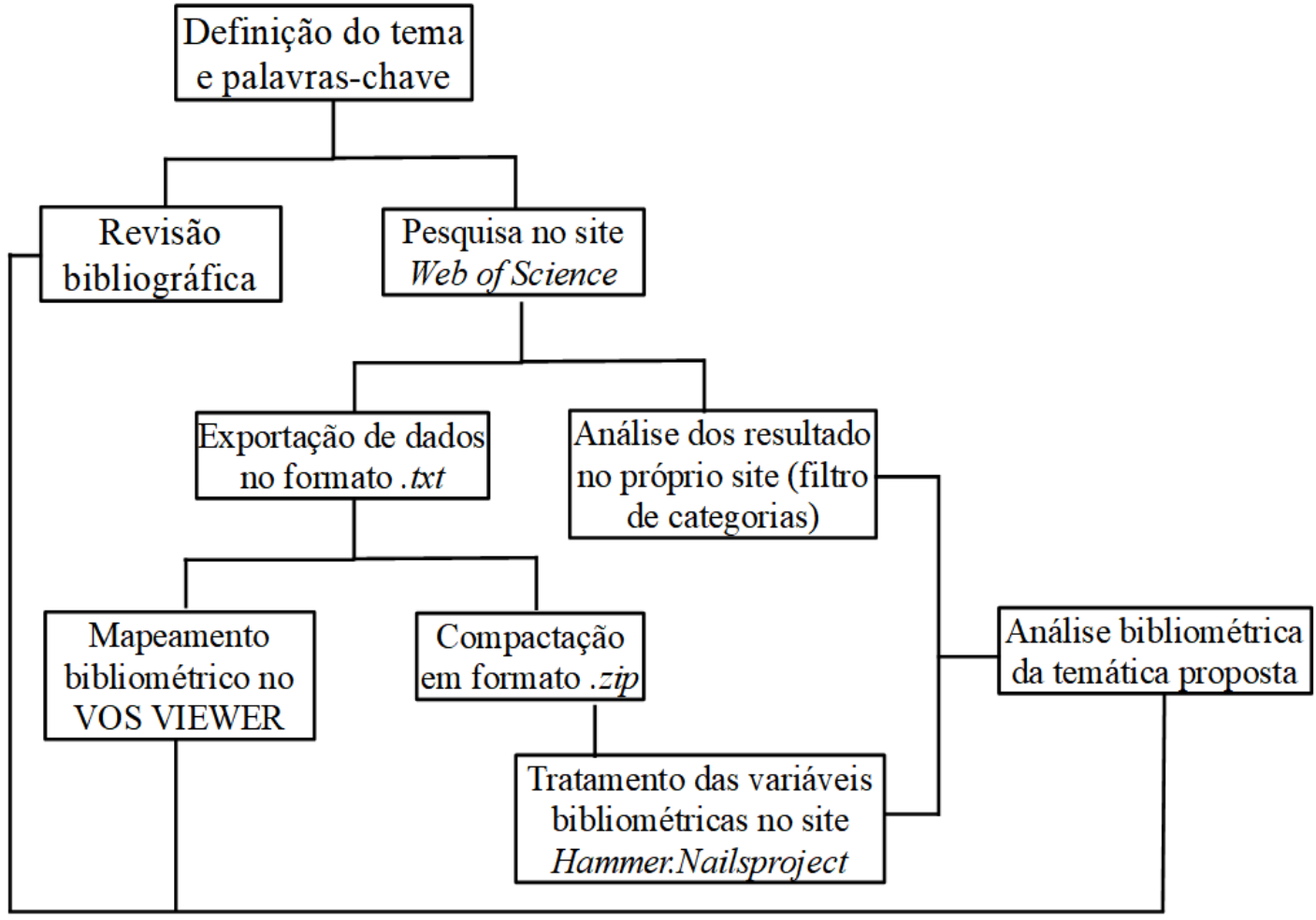

Figura 2 - Organograma metodológico

Foram usadas duas ferramentas remotas de análise, o aplicativo VOS Viewer para o mapeamento bibliométrico e a plataforma do Hammer.Nailsproject para a categorização e produção dos gráficos das variáveis. O VOS Viewer é um programa gratuito que foi desenvolvido para produzir e visualizar mapas bibliométricos de publicações, serve para realizar análises de volume de publicações com no mínimo 100 itens e seu o acrônimo VOS significa visualization of similarities (visualização de similaridades) (VAN ECK; WALTMAN, 2010). Sua principal função é fornecer aos usuários informações das forças de ligação ou similaridade estabelecida entre dois ou mais itens.

A plataforma Hammer.Nailsproject ou simplesmente Hammer é um sistema hipertextual executado por meio da internet automatizando a análise de rede para estudos bibliométricos, é gratuito e gera um compilado de gráficos e um relatório das variáveis analisadas, os dados também podem ser baixados no formato de planilhas.

\section{Análise das variáveis bibliométricas}

6.1. Rede de cocitação e citação 


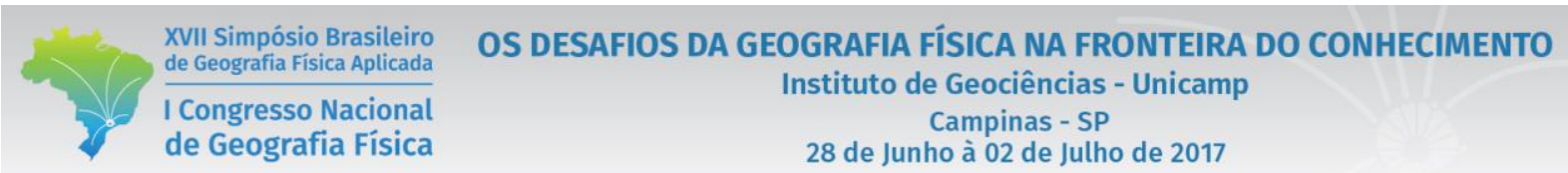

A frequência de cocitação estabelece uma rede de similaridade entre dois autores ou documentos deixando evidente uma estrutura de conhecimento percebida pelo citante, ou seja, quando dois autores são citados em uma publicação há uma afinidade de ideias, quanto mais esse episódio se repetir em outras publicações maior será a similaridade entre eles (GRÁCIO; OLIVEIRA, 2013). Em bibliometria essa similaridade também é chamada de força de ligação ou força de relação.

A análise bibliométrica destacou a precursora do Índice DRASTIC, Linda Aller, como a maior referência para os trabalhos sobre vulnerabilidade à contaminação das águas subterrâneas que fizeram uso desse método (Figura 3). Com mais de 116 citações, as maiores afinidades de ideias com as dela são representadas, primeiramente, pela cocitação Aller-Babiker e depois Aller-Gogu.

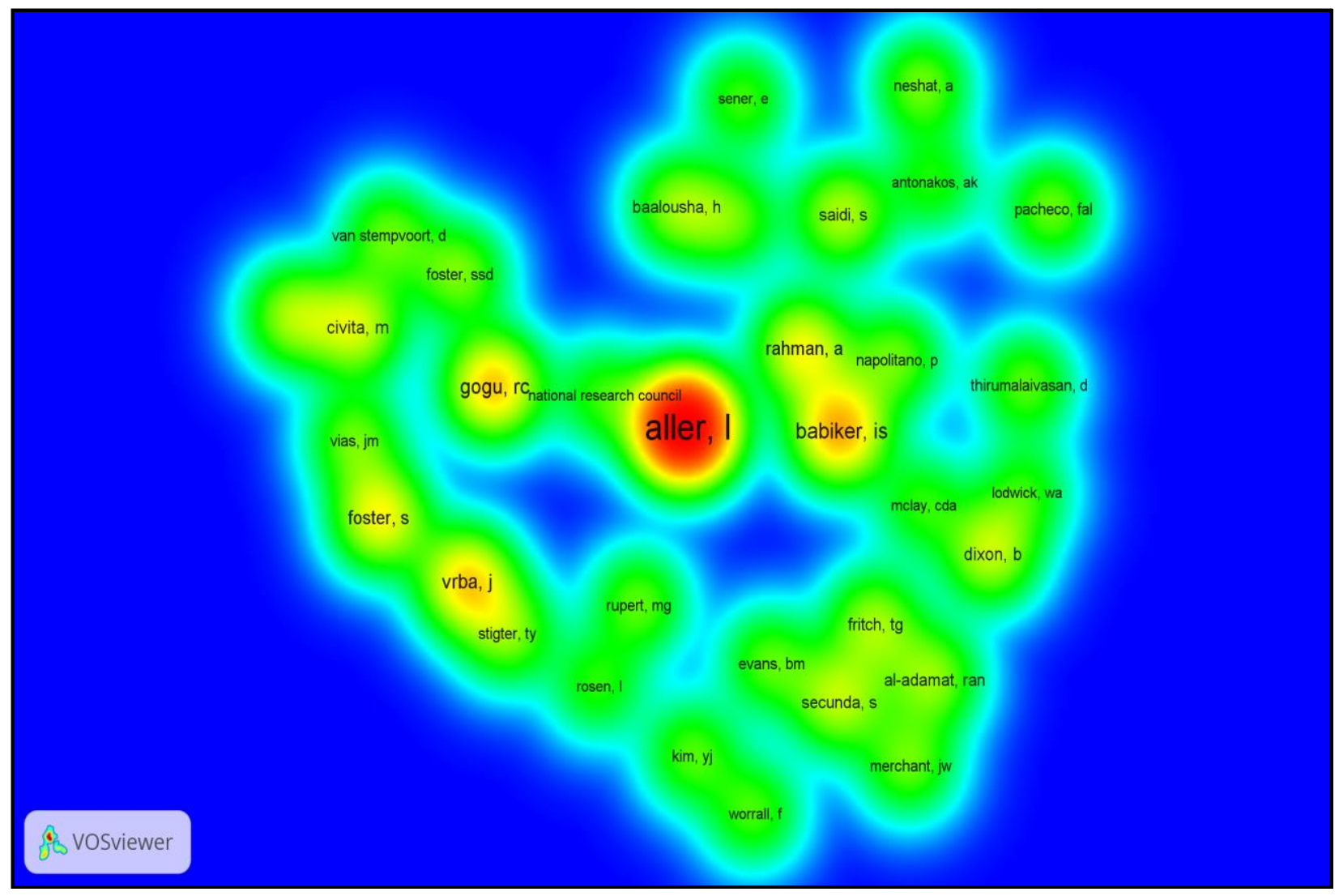

Figura 3 - Densidade de citação

O mapa de densidade fornece uma visão geral da estrutura da rede e chama atenção para os pontos mais importantes (VAN ECK et al., 2010). Nele, além de Aller, com 306 citações em cocitações, 6 outros autores se destacam na importância, são eles ordenadamente: Gogu com 116 citações, Babiker com 127 citações, Vrba com 107 citações, Rahman com 92 citações, Civita com 80 citações e Foster com 95 citações. 


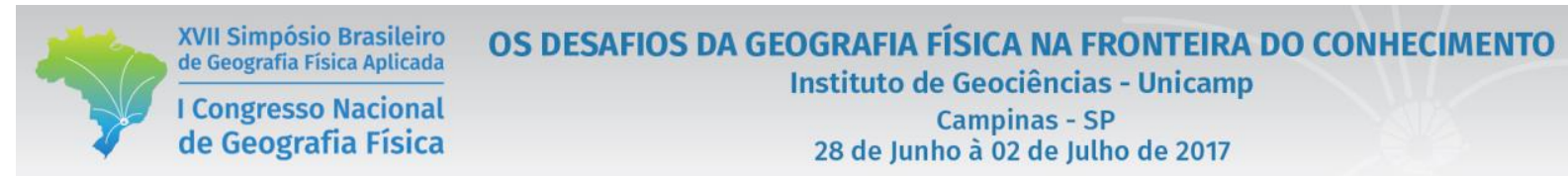

$\mathrm{Na}$ análise de cocitação, a ordem de importância não se baseia no número de citações mais na força de relação entre autores na colaboração científica, assim, Aller reflete 3.257 relações, Gogu 1.852 relações, Babiker 1.813 relações, Vrba 1.469 relações, Rahman 1.376 relações, Civita 1.324 relações e Foster 1.295 relações (Figura 4).

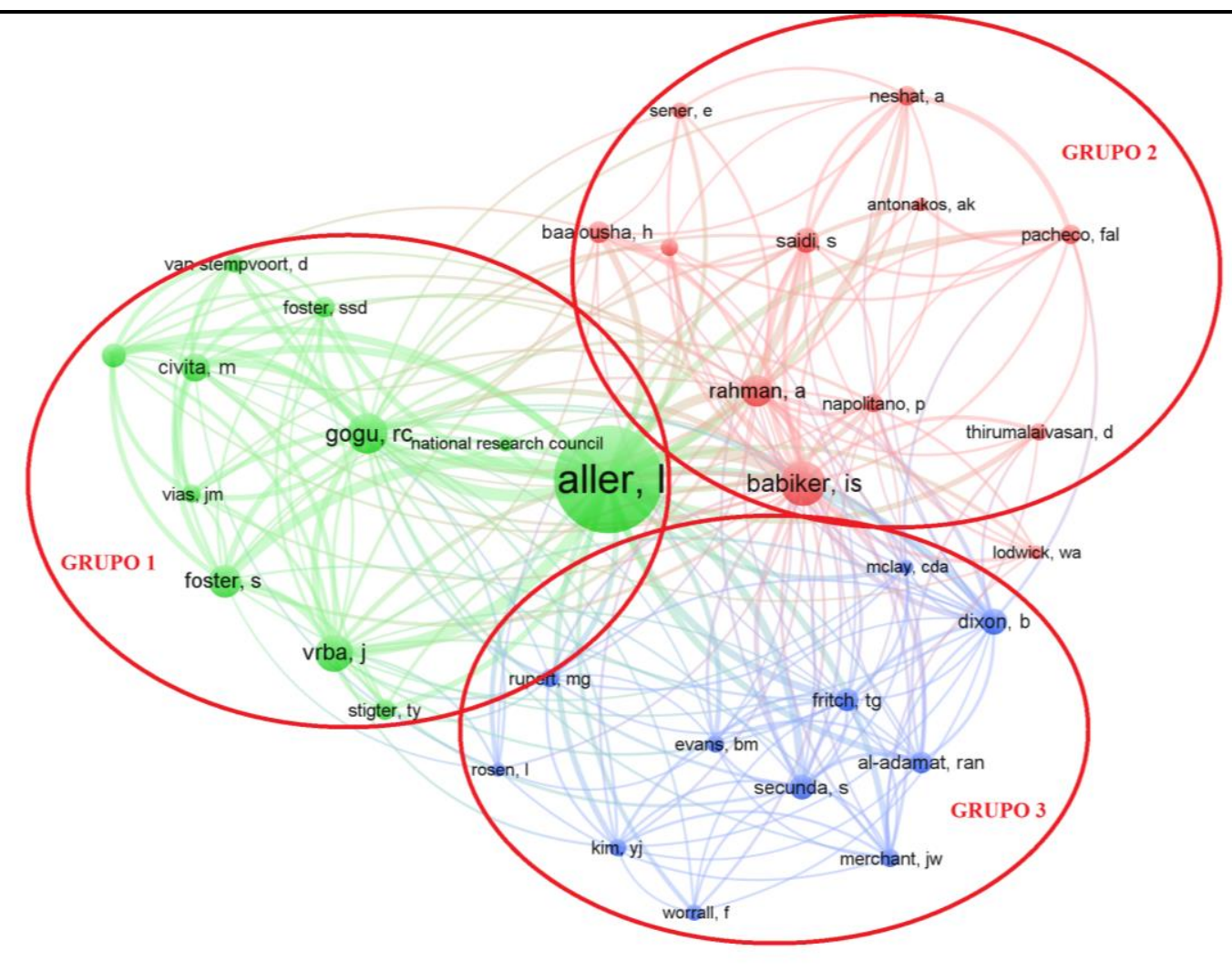

Figura 4 - Força de relação entre os autores.

$\mathrm{Na}$ pesquisa bibliométrica podem ser destacados dois tipos de mapas, os baseados nos gráficos e os baseados na distância. Nos mapas baseados em gráficos a distância entre os itens não precisa refletir relação entre eles e linhas podem ser desenhadas para estabelecer essa relação, por sua vez, nos mapas baseados em distância a posição dos itens estabelece uma relação entre eles, itens mais próximos têm mais similaridade que itens mais distantes e podem ser agrupados (clusters) (VAN ECK et al., 2010).

A figura 4 é um típico mapa baseado na distância, nela é possível identificar 3 grupos de força de relação entre os autores que foram citados no mínimo 40 vezes juntos.

O grupo 3 é o mais harmônico, sem a presença hegemônica de um autor mais consultados e pela maior proximidade entre eles. Todavia, a harmonia no grupo não significa que todos os autores possuem a mesma quantidade de ligação colaborativa e neste caso Secunda e Dixon se destacam sutilmente em relação aos demais, porém nada muito significativo. Os autores desse grupo possuem uma rede de relação 
muito diversificada entre eles e autores dos dois outros grupos, suas publicações concentram-se nas décadas de 1990 e início dos anos 2000.

O grupo 2 é marcado pela liderança, respectivamente, de Babiker e Rahman. Esses dois autores são os que possuem publicações mais antigas no grupo, em 2008 e 2005, que segue uma tendência de trabalhos publicados a partir dos anos 2000 e são os trabalhos mais atuais, as ligações mais fortes são com o grupo 3 e com Linda Aller.

O grupo 1 é o mais influente de todos, Gogu, Foster e Vrba exercem um segundo nível de domínio nas colaborações científicas, porém Aller é quem polariza a rede não somente no grupo 1, mas em todos os grupos. Ela seria a fonte difusora dos conhecimentos relacionado aos estudos com o Índice DRASTIC a partir dela os trabalhos na temática foram evoluindo até os dias atuais. O grupo não possui uma periodicidade exata nas publicações, mas foram os primeiros a publicar, seus trabalhos se concentram na segunda metade da década de 1980, na primeira metade da década de 1990 e na primeira metade dos anos 2000.

\subsection{Produção na área}

A produção de artigos na temática abordada teve um salto de 1987 a 2015, principalmente a partir da segunda década dos anos 2000 (Figura 5). No quinquênio 1987-1991 o volume de produção foi de 9 artigos dos quais se destaca "DRASTIC-A standardized system to evaluate groundwater pollution potential using hydrogeologic setting", de Linda Aller, foi o artigo que difundiu o método em questão. Até o ano de 2011 o volume de publicações correspondia a 45,8\%, e em cinco anos mais que dobrou, chegando a um crescimento de 53,6\% no quinquênio 2012-2016, sendo somente no ano de 2016 concentrado 38,6\% das publicações ao longo desses 30 anos (1987-2016) de análise.

O crescimento na produção coincide com os avanços computacionais e popularização da Internet, tornando mais acessíveis os bancos de dados, ferramentas remotas, otimização de informações e aplicativos que potencializam a produção científica. A III Revolução Industrial ou Revolução Técnicacientífica-informacional, que nos dotou de máquinas mais modernas e redes inteligentes, também intensificou a Globalização nas últimas décadas e com ela as atividades econômicas que se traduziram em uma maior supressão dos recursos naturais.

As consequências dessas transformações suscitaram mais estudos tanto para o interesse do capital (manutenção das atividades econômicas) quanto para o interesse social (preservação de recursos naturais básicos para a sobrevivência e bem-estar) via leis ambientais mais rígidas. O crescimento econômico tem 
sido foco de pesquisas que extrapolam os meios acadêmicos e políticos por se constituir em ponto estratégico para o desenvolvimento econômico e redução da pobreza (VIEIRA; VERÍSSIMO, 2009).

Os resultados apontaram a China (15,5\% do total de publicações) e a Índia (10,2 \% do total de publicações), ambos respetivamente com crescimento econômico de 9,4\% e 6,3\% no início dos anos 2000 (VIEIRA; VERÍSSIMO, 2009), como os países que mais publicam na temática. Esses países têm como características o grande contingente populacional e sérios problemas ambientais consequentes do impulsionamento econômico, gerado pelos padrões de consumo de uma pequena parcela da população mundial conduzida pelos países industrializados e a elite dos países em desenvolvimento (MARTINE; ALVES, 2015), e as desigualdades sociais que retratam os países emergentes, nesses casos os estudos possuem um caráter mais remediativo. Em terceiro lugar aparece os Estados Unidos (9,1\% do total de publicações), como grande potência econômica sua preocupação é manter a segurança hídrica e as atividades produtivas, seus estudos possuem um caráter mais preventivo.

\subsection{Autores que mais produziram}

A produtividade foi medida em uma escala de no mínimo 2 e no máximo 6 artigos e considerou apenas pesquisadores como autores principais, o que não significa que esses autores se limitaram a quantidade de publicações apresentadas aqui, mas foram esses os trabalhos que atenderam à busca com base nas palavras-chave estabelecidas.

Grande parte dos autores tiveram pelo menos a produção de 2 artigos na temática abordada, o destaque ficou para Aminreza Neshat, com 6 publicações, e Salwa Saidi e Liping Bai, ambos com 4 publicações (Figura 6). Foram feitas duas constatações, a primeira foi a que os autores, de modo geral, concentraram suas produções nas primeiras décadas dos anos 2000 e a segunda foi a que suas publicações não se limitaram ao exposto na figura 6 e os referidos autores possuem publicações em parceria na condição de coautores. Não fica claro se esse volume reduzido de produção é causado por uma iniciação recente na atividade científica, o que é pouco provável uma vez que existem autores com apenas 2 artigos publicados há 17 anos, o que pode indicar uma mudança na área de atuação de pesquisa ou mesmo uma diversificação nos temas de pesquisa na mesma área.

Produtividade não é igual à qualidade, de igual modo, os autores que mais produzem não necessariamente são os mais citados nas publicações da temática. Nesse ponto, os líderes se invertem em comparação ao ponto anterior, Salwa Saidi e Aminreza Neshat são, respectivamente, os mais citados com citações superiores a 60 . 


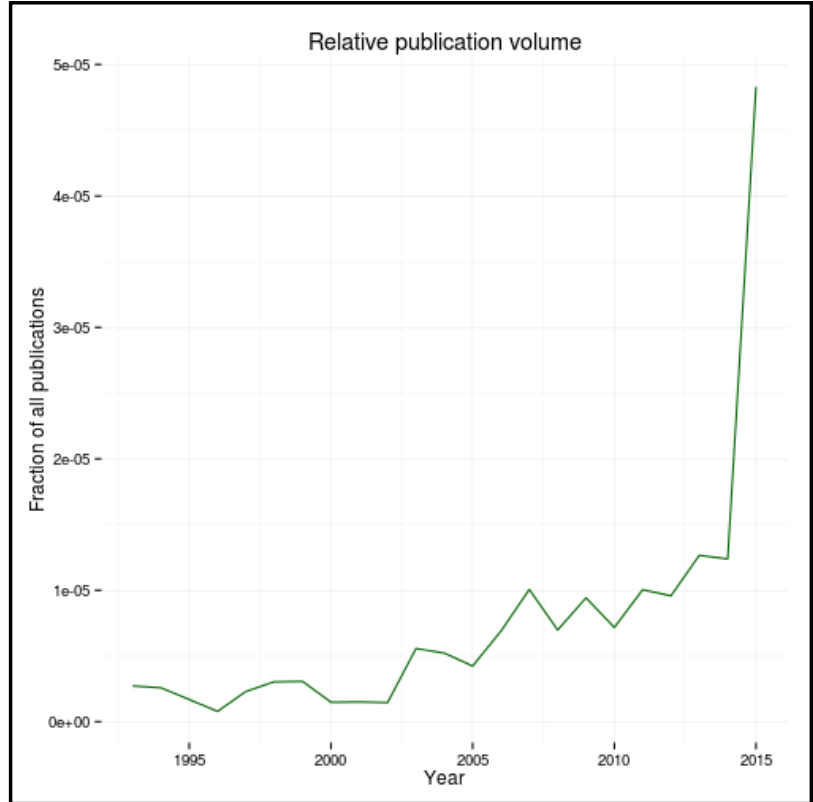

Figura 5 - Volume de publicação

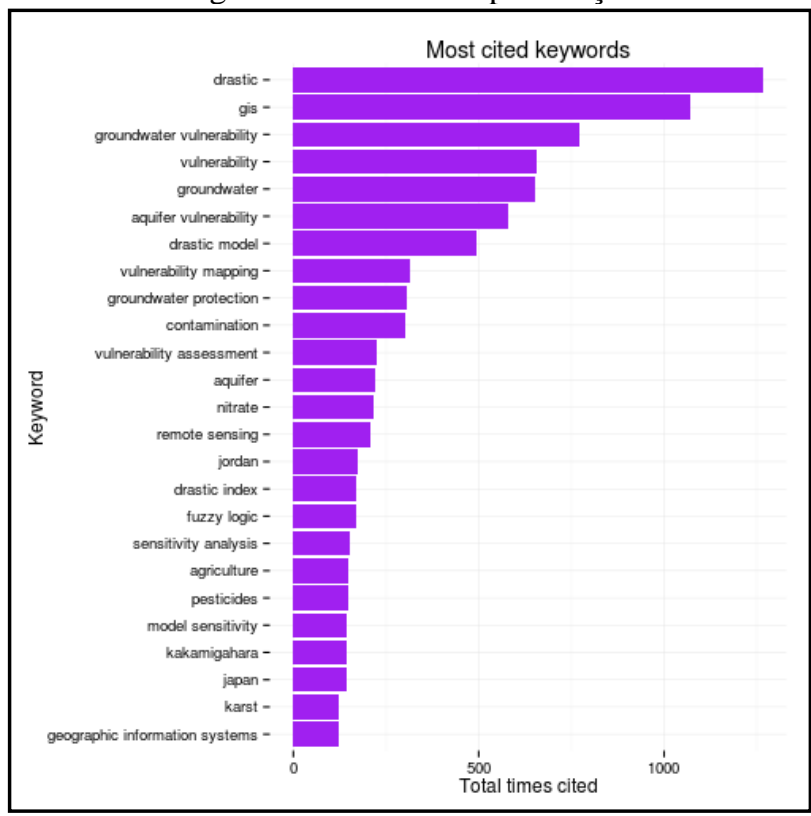

Figura 7 - Palavras-chave mais citadas

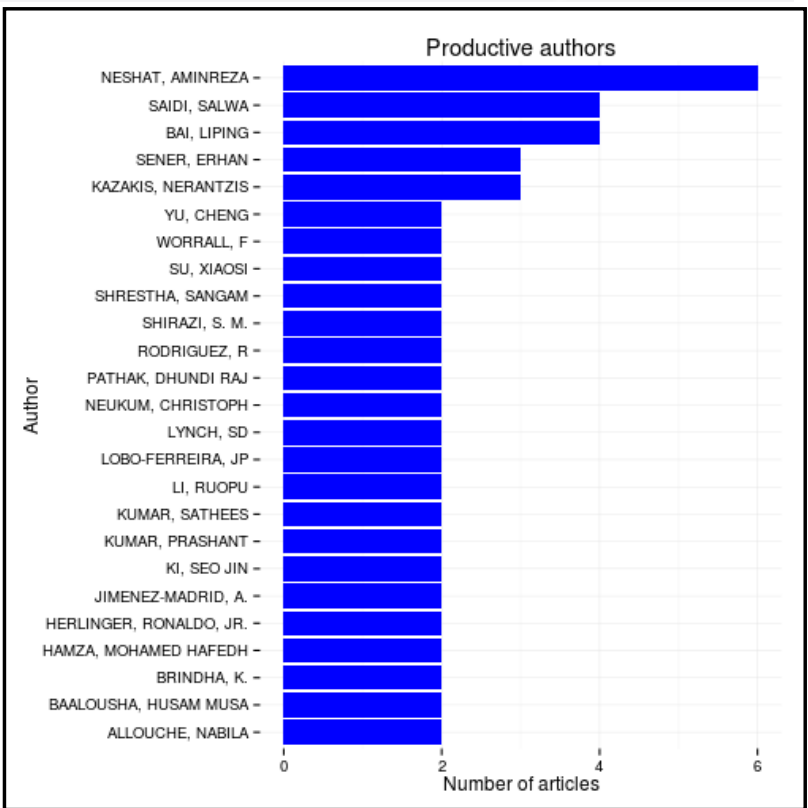

Figura 6 - Autores que mais publicaram

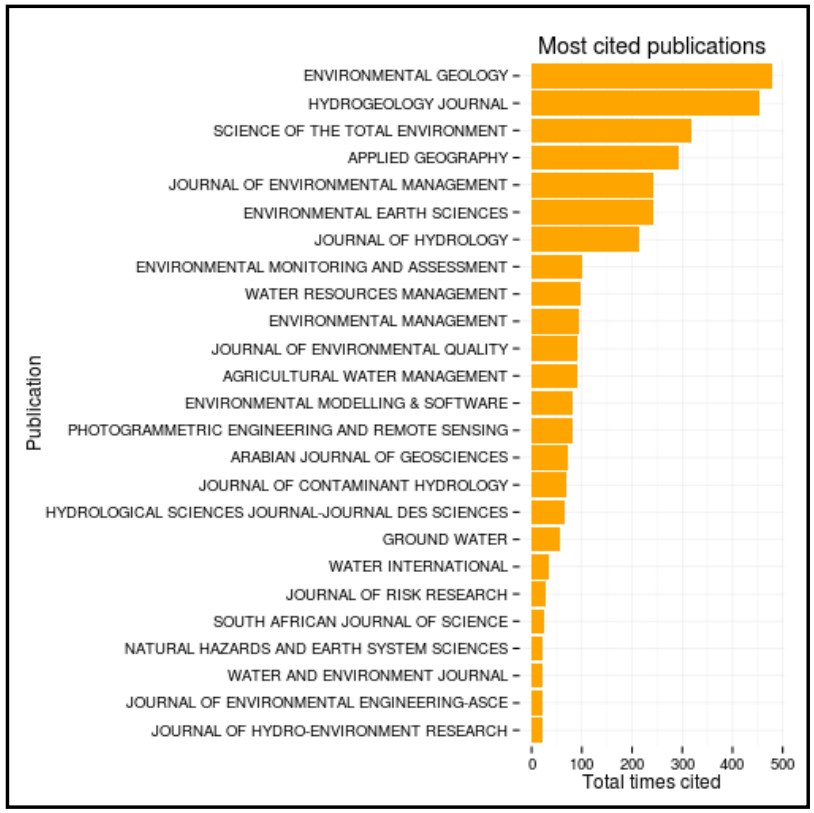

Figura 8 - Revistas mais importantes

\subsection{Palavras-chave mais citadas}

$\mathrm{Na}$ análise bibliométrica as palavras-chave mais citadas foram "DRASTIC", "GIS", "Groundwater Vulnerability”, “Vulnerability”, “Groundwater”, “Aquifer Vulnerability” e "DRASTIC Model” (Figura 7).

As palavras "DRASTIC" e "Groundwater" se destacam por se tratar da forma de investigação e do objeto a ser investigado, respectivamente, portanto, são palavras inevitáveis. "GIS" é a segunda palavras-chave 
mais citada e sua frequência reflete o aumento de publicações nas últimas décadas. Os Sistemas de Informações Geográficas agregaram mais qualidade aos trabalhos otimizando o processamento de dados e representações gráficas, principalmente quando as pesquisas exigem uma análise sistêmica de vários atributos, atualmente quase $100 \%$ das pesquisas utilizam essa ferramenta.

"Vulnerability" é outra palavra frequentemente citada, reforçando a condição pesquisada das águas subterrâneas. Ainda existe a discussão de que se estuda "o risco à contaminação" e não "a vulnerabilidade à contaminação", porém a pesquisa inicial no banco de dados do Web of Science apresentou um volume maior de trabalhos relacionados a vulnerabilidade do que a risco. O primeiro trabalho a usar "Vulnerability" como palavra-chave específica, nessa temática, foi "Aquifer vulnerability mapping using computerized systems in a Lombardian Piedmont area” publicado por Facchino e Riparbelli, em 1993.

\subsection{Revistas mais importantes e área de concentração das pesquisas}

As revistas mais importantes foram avaliadas pelo número de vezes em que os artigos nelas publicados foram citados em outras publicações. As quatro mais importantes, em ordem crescente, foram: "Enviromental Geology", "Hydrogeology Journal”, "Science of the Total Enviroment” e "Applied Geography”, sendo as duas primeiras citadas mais de 450 vezes e as duas últimas citadas mais de 290 vezes (Figura 8).

Todavia, o critério de revistas mais citadas não reflete o volume de artigos nelas publicados, nesse caso, as quatro mais importantes foram: "Enviromental Earth Sciences", "Enviromental Geology", "Arabian Journal of Geosciences" e "Science of the Total Enviromental", as duas primeiras concentram, respectivamente, mais de 45 e 25 artigos publicados, as demais revistas possuem volume de artigos publicados abaixo de 20 .

O volume de produção por área de pesquisa apontou a área de recursos hídricos como a mais importante, correspondendo a 52,9\% do total de publicações, ou seja, mais da metade. A área de ciências ambientais e ecologia ficou no segundo lugar concentrando 50,6\% do total de publicações, e as áreas de geologia e engenharia concentrando, respectivamente, $49 \%$ e 18,8\% do total de publicações. Cada área foi analisada no contexto de representatividade dela em relação ao volume total $(100 \%)$ e não comparada às demais áreas nesse volume, isso ocorreu devido às publicações apresentarem mais de uma área de pesquisa.

Os estudos de vulnerabilidade à contaminação das águas subterrâneas com o uso do Índice DRASTIC ainda são pequenos na área de geografia física, que concentra $2,6 \%$ do total de publicações. Na década de 1990 foram registradas duas publicações, mas somente a partir de 2008 houve um volume significativo com periodicidade de 2 anos entre as publicações. 


\section{Considerações finais}

A análise bibliométrica tem se constituído como uma ferramenta essencial no direcionamento da pesquisa científica, indicando tendências e fontes importantes de literatura, bem como fornece um panorama da temática pesquisada a nível internacional.

Os resultados, até o momento, indicam uma tendência do Índice DRASTIC em consolidar o conceito de vulnerabilidade entre os pesquisadores da área como a condição ou estado das águas subterrâneas a ser estudada, apontando ainda um crescimento de produção na temática, sobretudo, em países emergentes e em desenvolvimento.

Portanto, até o momento este trabalho fornece subsídios para analisar e avaliar as tendências do uso do Índice DRASTIC nas pesquisas que envolvam as águas subterrâneas, bem como para contribuir para a direcionamento de pesquisas futuras.

\section{Bibliografia}

ALLER, L. et al. DRASTIC: a standardized system to evaluate groundwater pollution potential using hydrogeologic settings. National Water Well Association, Worthington, Ohio, United States of America, 1987.

CARVALHO, G. Vulnerabilidade à Contaminação de Águas Subterrâneas: Comparação de Modelos Baseados no Método DRASTIC. Cadernos de Geografia, n. nº 32-2013, p. 289-299, 2013.

GAO, C. et al. A bibliometric analysis based review on wind power price. Applied Energy, v. 182, p. 602-612, 2016.

GRÁCIO, M. C. C.; OLIVEIRA, E. F. T. DE. Estudos de Análise de Cocitação de Autores: uma abordagem teórico-metodológica para a compreensão de um domínio. Anais XIV Encontro Nacional de Pesquisa em Ciência da Informação. Anais...Florianópolis: 2013Disponível em:

<http://enancib2013.ufsc.br/index.php/enancib2013/XIVenancib/paper/viewFile/105/162>

GUIGUER, N.; KOHNKE, M. W. Métodos para Determinação da Vulnerabilidade de Aquíferos. XII Congresso Brasileiro de Águas Subterrâneas. Anais...São Paulo: Águas Subterrâneas, 2002Disponível em: <file:///C:/Users/afons/Downloads/22314-80539-1-PB.PDF>

MARTINE, G.; ALVES, J. E. D. Economia, sociedade e meio ambiente no século 21: tripé ou trilema da sustentabilidade? Revista Brasileira de Estudos de População, v. 32, n. 3, p. 433-460, 2015.

OLIVEIRA, M. M.; LOBO FERREIRA, J. P. C. Cartografia da vulnerabilidade à poluição das águas subterrâneas do Concelho de Montemor-o-Novo utilizando om étodo DRASTIC. Lisboa: Laboratorio Nacional de Engenharia Civil (LNEC), 2002.

RICHTS, A.; VRBA, J. Groundwater resources and hydroclimatic extremes: mapping global groundwater vulnerability to floods and droughts. Environmental Earth Sciences, v. 75, n. 10, p. 926, 2016.

SELINUS, O. Geologia Médica. Geologia Médica no Brasil: efeitos dos materiais e fatores geológicos na saúde humana, animal e meio ambiente. Textos do 2005 Workshop Internacional de Geologia Médica. Anais...Rio de Janeiro: CPRM -Serviço Geológico do Brasil, 2006 
VAN ECK, N. J. et al. A comparison of two techniques for bibliometric mapping: Multidimensional scaling and VOS. Journal of the American Society for Information Science and Technology, v. 61, n. 12, p. 2405-2416, 15 dez. 2010.

VAN ECK, N. J.; WALTMAN, L. Software survey: VOSviewer, a computer program for bibliometric mapping. Scientometrics, v. 84, n. 2, p. 523-538, 2010.

VIEIRA, F. V.; VERÍSSIMO, M. P. Crescimento econômico em economias emergentes selecionadas: Brasil, Rússia, Índia, China (BRIC) e África do Sul. Economia e Sociedade, Campinas, v. 18, n. 3, p. 37, 2009. 